\title{
Museo alternativo-participativo, un modelo frente a la hegemonía cultural
}

Máximo Gómez Castells*

\section{Resumen}

En el trabajo se desarrolla una reflexión sociológica de la importancia del consumo cultural desde la perspectiva de la hegemonía alternativa en el discurso y la participación de los públicos. Al colocarse en esa perspectiva, se propone modificar las creencias de los museos y transformar sus prácticas desde la interacción como principio activo, que tenga lo productivo como fin de su accionar. Los comportamientos serían organizados con un pensamiento que establezca una situación de consumo, hermenéutica muy necesaria para articularse los museos en las sociedades contemporáneas.

\section{Desarrollo}

La concepción sociológica de cultura a la cual le es inherente, tanto la estructura social como el significado de la acción, mantiene un fuerte vínculo de relaciones con el patrimonio cultural, que desde el origen de su construcción epistemológica estableció un reto: preservar los productos que ilustraban la actitud creadora en el hombre como vía de incrementar su grado de humanización. Según este punto de vista, la construcción de significantes es una producción de sentido que provoca efectos de reconocimiento. Eliseo Verón llama de ese modo a las lecturas que en relación con determinadas condiciones de producción permite un texto. Queda de ese modo establecido un punto de vista muy productivo para ejercer la interpretación de lo social: recolocar el texto en el conjunto del proceso histórico de su surgimiento (producción-circulaciónconsumo), de ese modo el texto es estudiado en su integridad, en su coherencia y en sus contradicciones.

\footnotetext{
* Director del Museo Provincial de Granma.
} 
Verón hace una acotación que declara como una sentencia epistémica: el discurso del sujeto es el discurso del otro. Al autor de este trabajo le permitió encarar el problema discursivo que enfrentan los museos: al difundir la cultura es indispensable reflexionar la lectura que hará el otro, el público cultural donde se revelan los órdenes del significado que las representaciones construidas provocan: el concepto contenido en el signo, la operacionalización que permite alcanzar y la realidad que construye denominando los fenómenos sociales. De esa complejidad surgen las necesidades culturales como capacidades de los actores sociales para consumir la oferta cultural. El museo se establece en el complejo proceso descrito donde está presente la producción de discursos y su uso. Esa condición lo convierte en un instrumento para la socialización de conocimientos y la instalación de sensibilidades. Es decir, constituye un espacio de diálogo intercultural.

Al adentrarnos en el campo del intercambio de saberes, se manifiestan en él las formas concretas de relación entre individuos y la situación histórica que lo contextualiza. En esa realidad subyace el papel de la ideología como sistema de ideas, creencias y certezas que los individuos siguen para interpretar la realidad. Esa interpretación está mediatizada por la posición de clase, el hogar, el barrio o contexto social y los factores educacionales institucionales que forman en el individuo su psiquismo y su sociabilidad. Desde el surgimiento de la estratificación social se producen antagonismos que impiden un alto grado de humanización y convierten la cultura en mecanismo de dominación que obstaculiza la percepción de los intereses específicos de las clases. Los museos son dispositivos que operan con la cultura para devolver al ser humano las posibilidades de su desarrollo. Urge pensar en las condiciones y contenidos producidos en aras de evitar la producción de discursos cuya interpretación provoque una identificación con un status de distinción que esté instalando una perspectiva hegemónica no desde la política, sino desde el ámbito de lo cultural.

Frente a la escuela erigida como espacio para entrenar a los sujetos en comportamientos que les permita actuar en los escenarios sociales, se ubicó el museo como dispositivo donde se integra en armonía lo afectivo y lo racional, y donde era posible desarrollar una mayor magnitud de la sensibilidad que el conocimiento aporta a los actores sociales. Estas instituciones habían ejemplificado la potenciación que los objetos culturales producen. Regidos por un poder, habían establecido reglas para el acceso y con ello creado uno de 
los principales conflictos que se han reproducido al interior de los museos: el consumo del producto cultural está determinado por una competencia clasista, económica, cultural que, en este último caso, incluye lo social.

En la sociedad contemporánea, donde el poder institucional se ha diversificado, los dominios donde se instalan las representaciones exhiben las huellas de las condiciones ideológicas que definen el status de ese poder. Ese proceso de dominación colectiva crea - según Marx - necesidades falsas en contra de los intereses del propio sujeto. Esto ha dado lugar a una estructura de dominación que ha convertido las mercancías en símbolos de distinción. Los productos culturales, al entrar en relación con el universo del mercado, han sido objeto de estos efectos y otorgado un rango a los públicos que los polarizan en amantes de la cultura clásica o popular, pero es más grave apreciarlos como receptores pasivos o unilineales de un sentido que no revela el proceso en su totalidad.

Estas dicotomías representan una de las reminiscencias de las sociedades donde la inmovilidad social era una condición funcional. Ello es expresión de una conducta cómplice, que en la actualidad ubica en los estratos inferiores aquellos sectores sociales carentes de una tradición cultural familiar en lo clásico; y lo que es más desacertado: actuar desconociendo este factor negativo, que ha llegado hasta la teoría cultural para clasificar de inferior lo popular. Néstor García Canclini, advirtiendo la trascendencia del tema, explicaba: "Lo popular es en esta historia lo excluido: los que no tienen patrimonio, o no logran que sea reconocido y conservado (...), los espectadores de los medios masivos que quedan fuera de las universidades y los museos, incapaces de leer y mirar la alta cultura porque desconocen la historia de los saberes y estilos. Artesanos y espectadores, ¿son los únicos papeles asignados a los grupos populares en el teatro de la modernidad?’.

Al situar el campo de lo popular fuera de los museos y el patrimonio, este autor esta subrayando aquello que está ubicado al margen de una legitimidad social. En este caso no solo sin marcas en el discurso, sino carente de un comportamiento interpretativo de saberes producidos en el ámbito académico de las universidades, es decir, que en los museos existe un capital cultural inaccesible por la carencia de una competencia cultural en los sujetos de lo popular. Este constituye el fundamento de la construcción de un modelo de museo alternativo-participativo donde se allanen los obstáculos no de una 
clase social, sino de los diferentes estratos de la sociedad contemporánea para apropiarse de los conocimientos y sensibilidades de una realidad muy compleja.

Lo hegemónico alude a un proceso que no puede verse de modo simplista. Sobre todo, es necesario alejarlo de una homologación de lo ideológico. La práctica de la hegemonía presupone la existencia de formas alternativas que determinan la existencia de lo contrahegemónico. Raymond Williams la define como todo un cuerpo de prácticas y expectativas en relación con la totalidad de la vida: nuestros sentidos y dosis de energía, las percepciones definidas que tenemos de nosotros mismos y de nuestro mundo. La insistencia en lo significativo planteada revela la dimensión de lo cultural en el concepto; y ello conecta con lo social, con un proceso de construcción con fuente en la cotidianidad. Esta percepción racional lleva al autor citado a contrastarlo: es una "cultura", pero una cultura que debe ser considerada asimismo como la vívida dominación y subordinación de clases particulares.

La existencia de estos dos procesos (dominación y subordinación) al interior de la hegemonía provoca la sospecha de otros invisibles: una "oposición que suscita". Como subyacen originan una magnitud; y Williams certifica una hegemonía alternativa. Este término extraído de Gramsci alude a lo que este autor define como manera de revelar la democracia: "En el sistema hegemónico existe democracia entre el grupo dirigente y los grupos dirigidos, en la medida en que [el desarrollo de] la economía y, por lo tanto, la legislación que expresa tal desarrollo favorece el paso [molecular] de los grupos dirigidos al grupo dirigente". La posibilidad de un método que evidencie esa complejidad resulta una capacidad teórica y práctica por desarrollar mediante un modelo que transforme las carencias apreciadas en los museos en la contemporaneidad,

Ana Cousillas apreciaba la evolución de los museos en dependencia de una consecuente transformación de las creencias de sus profesionales, considerando pautas demasiado interiorizadas las siguientes:

- Identificación del guión con la narrativa lineal y el recorrido único.

- La concepción fisicalista de la observación.

- A mayor cantidad de público mayor éxito cognitivo de la exposición. 
Al considerar las manifestaciones apuntadas un efecto negativo de las normas vistas como leyes eternas, se devela un carácter tecnócrata que desde la creación del museo moderno en el siglo XIX mantiene rígida la construcción y producción de modos de actuación que ignoran la existencia de la relación dominación-oposición. Las fuentes contrahegemónicas, para Gramsci, se ubican en la necesidad de la clase obrera en "convertirse en una clase, y en una clase potencialmente hegemónica, contra las presiones y los límites que impone una hegemonía poderosa y existente". En lo cultural las formas alternativas tienen sus condiciones, límites, acentuaciones, oposiciones y formas de lucha enfrentadas por la hegemonía, que conviene estudiar para extraer sus lecciones y contextualizar los modos de construcción clasista real y no abstracta.

Para Williams la hegemonía es un orden colectivo, y jamás individual, cuando estamos hablando de condiciones de producción, pero no resulta así cuando se trata de condiciones de reconocimiento, que son las correspondientes al papel del público. Las ofertas culturales, en tanto herramienta de socialización, constituyen un campo de producción que debe integrarse al proceso de aprendizaje. Sin embargo, subsisten modos de interacción distantes del paisaje urbano contemporáneo y de los contenidos de la vida cotidiana caracterizados por la necesidad de reflexionar, interpretar y vivir las sensibilidades. La preocupación por la cohesión social de los dispositivos formativos predomina en las reflexiones acerca de la escuela y trasciende a la cultura. La mejicana Lucina Jiménez expresa: "Necesitamos que nuestros hijos y jóvenes puedan interactuar en contextos de conflicto, de inestabilidad, de fragmentación y de diversidad, en ambientes tecnológicos y altamente competitivos".

Para esos retos no se ha diseñado una concepción de las prácticas que permita instalar las capacidades que demandan los sujetos. De aquellos se desconoce necesidades, hábitos, territorialidades y muchos indicadores que permitirían reinventar los modos de actuación institucional. Los museos son teóricamente el espacio para la interacción cultural y para el ejercicio del derecho al desarrollo, a la comunicación y al comportamiento ciudadano. Los recursos humanos y materiales destinados no han elevado sus medios teóricos para enfrentar las realidades construidas y son intermitentes las calidades de los productos que se ofrecen, así como generalmente poco representativos en cantidad y calidad los públicos cautivos. 
El análisis cultural es el ámbito donde se obtiene la producción científica que realiza la institución en sus representaciones. Los instrumentos epistemológicos y metodológicos tendrán esta última como fuente para la articulación con los contextos descritos; sobre todo si se experimenta la manera de producir "la parte más difícil e interesante de todo análisis cultural... es la que procura comprender lo hegemónico en sus procesos activos y formativos, pero también en sus procesos de transformación. Las obras de arte, debido a su carácter fundamental y general, son con frecuencia especialmente importantes como fuentes de esta compleja evidencia". La construcción de lo activo y transformativo en lo hegemónico es alcanzar condiciones para, desde lo alternativo, viabilizar otra participación de mayor significado estructural.

La participación responderá a dimensiones que estén en consonancia con la lógica del cambio cultural. Las aportaciones de los textos con sus huellas históricas y de sentido son los hechos donde operan la recepción y el receptor como momentos teóricos, los que atravesaría la interpretación para producir las respuestas a los mensajes. Los campos del modelo participativo están en las funciones del museo y la experiencia de sus prácticas, que han tenido en el intercambio cultural la herramienta de medición de mayor eficacia y longitud.

Los límites que se pueden establecer a la lectura hegemónica tienen como origen la naturaleza del discurso institucional; de ese modo se desplazaría la acción de actores y agentes por la diversidad significativa y su capacidad para mostrar campos simbólicos que explican la dinámica social del contexto, y, por otro borde, será necesario arribar a la singularidad de las representaciones en la multiplicidad de sus marcas de sentido, como meta para configurar la noción de hecho cultural. Los límites propuestos orientarían las prácticas y permitirían estudiar los procesos desde una posición que va de la dominación a lo alternativo para ver en ello la imagen total del sujeto concreto de una colectividad. La producción de estos elementos viabilizaría la construcción de situaciones que orienten la acción.

El desconocimiento de los fundamentos de la orientación como nivel institucional y la motivación como individual ha provocado, en la realidad del ámbito empírico, una tendencia al rechazo, en tanto manera de selectividad que tiene su base en el estrecho margen de alternativas, propuesto en las situa- 
ciones construidas. Los discursos reiterativos no favorecen la aparición de nuevos significados que le propongan metas e intereses que se deben alcanzar a los públicos, que ven distantes la gratificación de sus necesidades. En la construcción de las situaciones de consumo cultural urge colocar no solo la adquisición de información, sino nuevas pautas de orientación que viabilicen lo que Parsons define como formas de ver, querer, evaluar. En el contexto contemporáneo las formas de hacer se incorporan entre las normas de aprendizaje debido a la independencia que los medios tecnológicos han incorporado a los sujetos. Por tales razones, los museos deben crear condiciones para dar continuidad a los procesos de mundialización de la cultura y viabilizar lo que Ana Cousillas denomina "el compromiso activo con los objetos", es decir, colocar al público en posición reflexiva ante problemas que le proponga la institución en sus ofertas.

Desde la década de los años ochenta existe un enfoque de intervención social. Se presenta para los museos urgida de una responsabilidad con su entorno, que abandona el pensamiento hacia el interior y lo coloca en la comunidad vista como contexto de actuación. "Si los museos no consiguieran responder al cambio social y reflejarlo, dejarían de justificar el apoyo público", afirma en Londres Kennet Hudson, consultor de la Unesco, para quien la sostenibilidad de la institución por el Estado está condicionada a su capacidad de participación en los problemas sociales. Ante un discurso nacional en los temas, la alternativa propone una acentuación que tiene, en este caso, en lo local y en los nichos culturales de las clases, las huellas que colocarán al sujeto en una relación de lo vivido con lo representado. Dicha relación abre campos de sentido en la denominación de fenómenos reales, en el uso de las experiencias de lenguaje y en la visibilidad de los imaginarios. Esa gramática del reconocimiento es favorecedora de una actitud hermenéutica que servirá, a su vez, de entrenamiento social.

La colocación de condiciones para el aprendizaje en los museos dio lugar a una práctica estructural: la creación de departamentos educativos para formar capacidades de apreciación en los asistentes, entrenarlos en la definición del patrimonio y habituarlos a prácticas consideradas complementarias porque educan de manera informal y pueden no centrar su acción en los fondos museales. Esa resulta una de las modificaciones de creencias más urgidas de transformación que el modelo alternativo pretende asumir; parte de la 
importancia de la acción cultural como prácticas culturales. En estas los sujetos operan con las representaciones que - según Thompson - son puntos de referencias comunes en una cultura que se extiende más allá de la interacción social; forman un tejido denso de experiencias comunes y nutren la memoria colectiva. La trascendencia que una práctica genera reside en el carácter interpretativo de esas representaciones; ella opera sobre objetos y enunciados significativos, que provocan al sujeto a una producción de respuestas donde se revela la asimilación y estructuración de la experiencia. Con la mirada colocada en el extremo público son diversos los enfoques metodológicos, pero subyace una percepción residual: es necesario producir el sujeto consumidor, el receptor competente, para un discurso generado desde las leyes del signo. Los especialistas franceses proponen una concepción profunda sustentada en preceptos antropológicos: la ecomuseología, que propugnaba la participación de la propia población en la creación del museo, un museo referido a su territorio. Una construcción como esa privilegia el sentido estructural del discurso, pero desplaza el consumo hacia el activismo social de la institución, con lo cual se concibe la producción como una interacción con el contexto. La aportación que la ecomuseología realiza a un modelo alternativo se puede definir como sustantiva porque representa el límite macrosociológico de la participación. Es a la vez una escala alta de la acentuación, pero no constituye todas las posibilidades discursivas porque parece sustentarse en lo popular.

En el caso de los museos, esta idea se articula con las transformaciones ocurridas en el concepto de patrimonio y en las funciones de los museos. La tradicional visión del patrimonio como herencia se cuestiona por estar representada una parte de la sociedad en los bienes seleccionados. Un déficit de esa magnitud es una de las causas que socavan la validez de los argumentos para el ejercicio taxonómico de qué bienes pueden alcanzar la categoría de patrimonio. La fuente originaria de esa inconsecuencia se ubica en una construcción hegemónica de lo cultural. Esa manifestación de lo hegemónico ha lastrado también al patrimonio, y, durante mucho tiempo, en las instancias teóricas se consideró inferior el campo denominado inmaterial de este. En la actualidad se opera asincrónico en las prácticas culturales institucionales, pues su presencia en las acciones aparece en desventaja en relación con las expresiones del patrimonio material.

En relación con los museos - según Ana María Cousillas - hay un desplazamiento en su concepción, y son vistos como instancias de reflexión y recuperación de saberes no objetivables, pero presentes en las representaciones del mundo 
social. Las nuevas funciones asignadas a ellos están dirigidas a la dimensión representacional de los bienes, lo cual es coherente con su finalidad en la consideración de los fines clasistas y su legitimación integradora de los estratos constituyentes de la sociedad en general. Por otro lado, los conflictos y tensiones ocurridos en el interior del campo cultural pueden ser manejados con mayor justicia desde la definición de patrimonio cultural propuesta por Cousillas: repertorios de bienes con determinados sentidos histórica y/o contemporáneamente atribuidos, según los casos, pero que producen diferentes y nuevos efectos de significación y acciones de interpretación, según las competencias cognitivas y simbólicas de los receptores.

Los hechos hasta aquí presentados acerca de los cambios ocurridos en las dimensiones funcionales de los museos, en el concepto del patrimonio, las inserciones pedagógicas en su estructura determinan modificaciones al interior del campo, pues la incorporación de nuevos actores: los pedagogos, que traen instalada una capacidad generatriz de prácticas culturales con mucho énfasis en lo didáctico, modifica el sistema de relaciones y de papeles en tanto estos atenderán a la población educacional y los conservadores se concentrarán en la atención a los bienes. Esa reestructuración hará de los estudiantes un público consumidor numeroso, que tendrá como fines impuestos por los profesores obtener conocimientos más que recreación, mientras que para ellos el ocio sigue operando como un derecho en la visita. Una necesidad de servicio con esa naturaleza exige una investigación de lo local que esté signada por la producción científica institucional, desafío que no siempre los agentes están en condiciones de ofrecer en una gama de saberes.

Las ideas esbozadas por Bourdieu, acerca de la correspondencia entre el capital escolar y el cultural, adquieren vigencia y se incorporan como requerimientos para dotar a la institución de los papeles graduados en autoridad que demanda el conocimiento de los fondos. Una conclusión es obvia: el diseño de un museo responde a fines estratégicos, con dotaciones de productores y mediadores capaces. Al reflexionar el campo museológico, es decir, el de los públicos internos, se requiere pensar en las fuerzas actuantes cuyas posiciones responden a estrategias estructuradas desde el capital cultural que se disponen a socializar. Es un asunto que posee mucha fertilidad en la realidad cubana donde concurren factores no solo económicos en la movilidad estructural de la sociedad, sino sociales. Para los públicos culturales surgen índices que ilustran otro modo de lucha por el capital cultural, como son los fines asociativos determinados por la afinidad de papeles en una etapa de la vida; 
comportamiento estructurados en un ámbito familiar correspondiente a un sector profesional y algunos residuales de estructuras sociales correspondientes a tiempos de otro modelo social. La gama de cosas (conscientes, inconscientes y simbólicas) que puede escoger con su acción el sujeto del patrimonio son un horizonte de comportamientos que, desde el inconsciente, obligan a visitar un museo de historia regional o un sitio histórico para interactuar con los objetos simbólicos. 


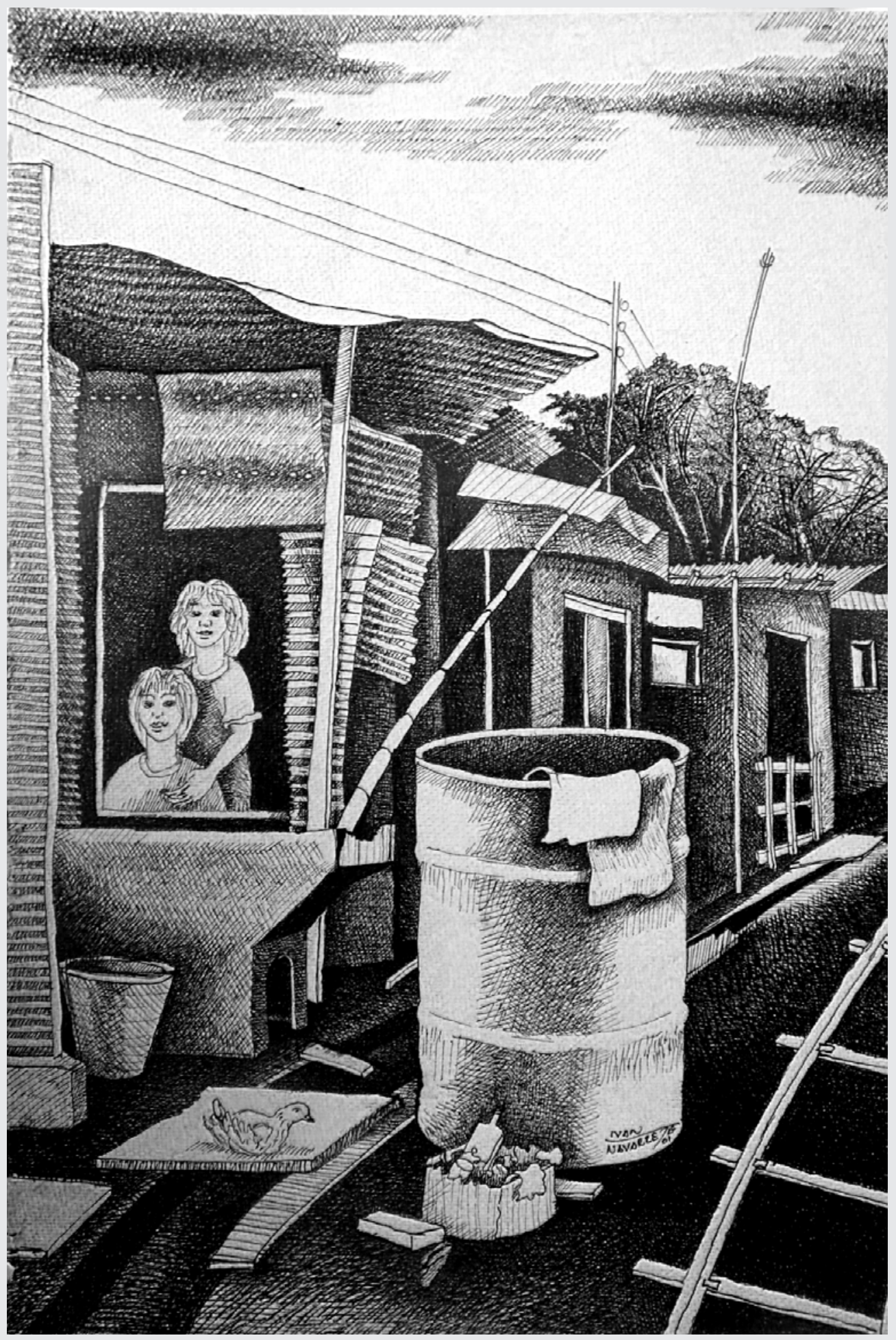

